\title{
Meta-analysis demonstrates association between Arg72Pro polymorphism in the $P 53$ gene and susceptibility to keloids in the Chinese population
}

\author{
Y. Wu ${ }^{1 *}$, B. Wang ${ }^{1 *}$, Y.H. Li ${ }^{1}$, X.G. Xu' ${ }^{1}$ Y.J. Luo ${ }^{1}$, J.Z.S. Chen ${ }^{2}$, \\ H.C. Wei ${ }^{3}$ X.H. Gao ${ }^{1}$ and H.D. Chen ${ }^{1}$ \\ ${ }^{1}$ Department of Dermatology, \\ The First Affiliated Hospital of China Medical University, \\ Shenyang, P.R. China \\ ${ }^{2}$ Sheftel Associates Dermatology, Tucson, AZ, USA \\ ${ }^{3}$ Department of Dermatology, Mount Sinai Medical Center, New York, NY, USA \\ *These authors contributed equally to this study. \\ Corresponding author: H.D. Chen \\ E-mail: chenhd@cae.cn
}

Genet. Mol. Res. 11 (2): 1701-1711 (2012)

Received October 7, 2011

Accepted February 8, 2012

Published June 29, 2012

DOI http://dx.doi.org/10.4238/2012.June.29.2

\begin{abstract}
Although there is evidence suggesting genetic susceptibility for keloids, studies investigating the association between Arg72Pro polymorphism in the P53 gene and tendency to form keloids have given variable results. We made a meta-analysis of the effects of P53 Arg72Pro polymorphism on keloid risk in the Chinese population by conducting searches of the published literature in Pubmed, Embase, CBMdisc, and CNKI databases up to June 2011. Six studies were included in the meta-analysis, with a total of 359 keloid cases and 493 healthy controls. Meta-analysis results, respectively in the PCR-reverse dot blot and PCR-RFLP subgroups, showed significant associations between P53 Arg72Pro polymor-
\end{abstract}


phism and susceptibility to keloid in the comparisons of Pro allele vs Arg allele (odds ratio $(\mathrm{OR})=2.29,95 \%$ confidence interval $(\mathrm{CI})$ $=1.45-3.60 ; \mathrm{OR}=0.74,95 \% \mathrm{CI}=0.56-0.98) ;$ Pro/Pro $v s$ Pro/Arg $+\operatorname{Arg} / \operatorname{Arg}(\mathrm{OR}=2.91,95 \% \mathrm{CI}=1.88-4.53 ; \mathrm{OR}=0.54,95 \% \mathrm{CI}=$ 0.32-0.92); Pro/Pro vs Arg/Arg $(\mathrm{OR}=2.79,95 \% \mathrm{CI}=1.54-5.06$; OR $=0.51,95 \% \mathrm{CI}=0.28-0.92) ;$ Pro/Pro $v s$ Pro $/ \mathrm{Arg}(\mathrm{OR}=2.85,95 \% \mathrm{CI}$ $=1.75-4.63 ; \mathrm{OR}=0.57,95 \% \mathrm{CI}=0.32-0.99)$. We conclude that the Pro allele of P53 Arg72Pro polymorphism is a risk factor for keloids in the Chinese population.

Key words: P53 codon 72 polymorphism; Susceptibility; Keloid;

Meta-analysis

\section{INTRODUCTION}

Keloids are benign fibroproliferative dermal tumors unique to humans, and usually develop following an abnormal wound healing process (Bayat et al., 2003). Unlike hypertrophic scars, keloids are locally aggressive and characteristically extend beyond the original wound boundary (Atiyeh et al., 2005). They often show high recurrence rates and are refractory to therapeutic modalities (Butler et al., 2008). The etiology of keloids is commonly thought to be related to fibroblast dysfunction. Compared to fibroblasts isolated from a normal wound, keloid fibroblasts overproduce type I procollagen and over-express some growth factors such as transforming growth factor $\beta$ and vascular endothelial growth factor (Marneros and Krieg, 2004). Besides, these fibroblasts demonstrate dysregulation of apoptosis-related genes such as P53 (Sayah et al., 1999; De Felice et al., 2007).

The $P 53$ gene is located at $17 \mathrm{p} 13$ and encodes a $53-\mathrm{kDa}$ protein of 393 amino acids. The P53 gene or protein is implicated in controlling the cell cycle and DNA synthesis and repair, as well as programmed cell death (apoptosis) (Menezes et al., 2010). Furthermore, P53 polymorphism is likely to be relevant to the development of skin cancers. For example, the arginine (Arg) allele at codon 72 may affect the risk of non-melanoma skin cancer in contrast to proline (Pro) (McGregor et al., 2002; Pezeshki et al., 2006).

A previous study at the protein level showed a higher level of P53 protein accompanying a lower rate of apoptosis in keloid lesions or keloid fibroblasts compared to normal controls (Ladin et al., 1998). A study at the gene level revealed some detectable hotspot mutations at the P53 gene codon 72 in keloid lesions and cultured keloid fibroblasts (Saed et al., 1998). In addition, molecular epidemiological studies have been conducted to investigate the association between P53 Arg72Pro polymorphism and susceptibility to keloid disease, but the results remain inconsistent.

There is a high prevalence of keloids among Afro-descendants, Asians and Hispanics (Al-Attar et al., 2006). Population-based studies indicate that the Pro allelic form is most prevalent in dark-skinned races and least prevalent in those with white skin, with a clear and consistent decline in the prevalence of the Pro allele with increasing latitude (Sjalander et al., 1995). The present study was aimed at investigating the role of P53 Arg72Pro polymorphism in genetic predisposition to keloids, via a meta-analysis from all eligible case-control studies published to date. 


\section{MATERIAL AND METHODS}

\section{Literature search strategy}

A search of Pubmed, Embase, CBMdisc, and CNKI databases was performed to retrieve papers linking P53 Arg72Pro polymorphism and susceptibility to keloids in Chinese populations available up to June 2011 without language restrictions, using the following query: ["P53 genes" or "Tumor suppressor genes" or "TP53 Genes"] and ["Polymorphism, Genetic" or "Polymorphism, Single-Stranded Conformational" or "Polymorphism, Single Nucleotide" or "Polymorphism, Restriction Fragment Length" or "Amplified Fragment Length Polymorphism Analysis" or "DNA Copy Number Variations"] and ["Keloid" or "Keloids" or "Scar"]. The reference lists of major textbooks, review articles, and included articles were identified through manual searches to find other potentially eligible studies.

\section{Inclusion and exclusion criteria}

Studies were included in this meta-analysis if they met the following criteria: 1) casecontrol study that addressed keloid cases and healthy controls; 2) studies that evaluated the association between P53 Arg72Pro polymorphism and susceptibility to keloids in Chinese populations; 3) studies that included sufficient genotype data for extraction, and 4) healthy controls were in Hardy-Weinberg equilibrium (HWE). Studies were excluded from consideration if: 1) not case-control studies that evaluated the association between P53 Arg72Pro polymorphism and susceptibility to keloids in Chinese populations; 2) case reports, letters, reviews, and editorial articles; 3 ) studies that were based on incomplete raw data and no usable data reported; 4) duplicate data were contained in the studies; 5) family-based design, and 6) healthy controls were not in HWE.

\section{Data extraction}

Using a standardized form, data from published studies were extracted independently by two reviewers (Wu Y and Wang B) to populate the necessary information. Disagreements were resolved by discussion. From each of the included articles the following information was extracted: first author, year of publication, study design, sample, diagnostic criteria, source of controls, number of cases and controls, detection methods, genotype frequency, and evidence of HWE in controls. For conflicting evaluations, an agreement was reached following a discussion.

\section{Quality assessment of included studies}

The quality of papers was also independently assessed by two reviewers (Wu Y and Wang B) based on the STROBE quality score systems (Vandenbroucke et al., 2007). Thirty items relevant to the quality appraisal were used for assessment in this meta-analysis, scores ranged from 0 to 30 (Table 1). Any discrepancies between the two reviewers were resolved by discussion and consultation with a third reviewer ( $\mathrm{Li} \mathrm{YH})$. 
Table 1. Scale for quality assessment based on the STROBE quality score systems.

\begin{tabular}{|c|c|c|}
\hline \multirow{2}{*}{$\begin{array}{l}\text { Criterium items } \\
\text { TITLE AND ABSTRACT }\end{array}$} & \multicolumn{2}{|c|}{ Score 0 to 30} \\
\hline & & \\
\hline (1) Indicate the study's design (case-control) in the title or the abstract & $\square 0$ & $\square 1$ \\
\hline (2) Provide an informative and balanced summary of the study in the abstract & $\square 0$ & $\square 1$ \\
\hline \multicolumn{3}{|l|}{ INTRODUCTION } \\
\hline (3) Explains the scientific background and rationale for the investigation & $\square 0$ & $\square 1$ \\
\hline (4) States specific objectives, including any prespecified hypotheses & $\square 0$ & $\square 1$ \\
\hline \multicolumn{3}{|l|}{ METHODS } \\
\hline (5) Present key elements (objects, gene, detection methods, etc.) of study design & $\square 0$ & $\square 1$ \\
\hline (6) Describe the setting, locations, relevant dates and data collection & $\square 0$ & $\square 1$ \\
\hline (7) Give the eligibility criteria and numbers of cases & $\square 0$ & $\square 1$ \\
\hline (8) Give the eligibility criteria and numbers of controls & $\square 0$ & $\square 1$ \\
\hline (9) Give the sources of cases and controls & $\square 0$ & $\square 1$ \\
\hline (10) Clearly define all outcomes, exposures, potential confounders, etc. & $\square 0$ & $\square 1$ \\
\hline (11) Give sources of data and details of methods of assessment & $\square 0$ & $\square 1$ \\
\hline (12) Describe any efforts to address potential sources of bias & $\square 0$ & $\square 1$ \\
\hline (13) Explain and describe the estimation of the study size & $\square 0$ & $\square 1$ \\
\hline (14) Explain how quantitative variables were handled in the analyses & $\square 0$ & $\square 1$ \\
\hline (15) Describe all statistical methods used in the study & $\square 0$ & $\square 1$ \\
\hline (16) Explain how missing data were addressed & $\square 0$ & $\square 1$ \\
\hline (17) Describe any sensitivity and subgroup analyses & $\square 0$ & $\square 1$ \\
\hline (18) Hardy-Weinberg equilibrium (HWE) of control group was assessed & $\square 0$ & $\square 1$ \\
\hline \multicolumn{3}{|l|}{ RESULTS } \\
\hline (19) Report the eligible number of cases and controls & $\square 0$ & $\square 1$ \\
\hline (20) Give a flow diagram of case selection & $\square 0$ & $\square 1$ \\
\hline (21) Give baseline characteristics of study participants & $\square 0$ & $\square 1$ \\
\hline (22) Describe the baseline comparability of study participants & $\square 0$ & $\square 1$ \\
\hline (23) Indicate the number of participants with missing data & $\square 0$ & $\square 1$ \\
\hline (24) Give each variant frequency of cases and controls & $\square 0$ & $\square 1$ \\
\hline (25) Describe any confounders that were adjusted and why they were included & $\square 0$ & $\square 1$ \\
\hline (26) Report subgroups or sensitivity analysis results & $\square 0$ & $\square 1$ \\
\hline \multicolumn{3}{|l|}{ DISCUSSION } \\
\hline (27) Summarizes key results with reference to study objectives & $\square 0$ & $\square 1$ \\
\hline (28) Discusses limitations of the study and sources of potential bias & $\square 0$ & $\square 1$ \\
\hline (29) Discusses the generalizability of the study results & $\square 0$ & $\square 1$ \\
\hline \multicolumn{3}{|l|}{ OTHER } \\
\hline (30) Gives the source of funding and the role of the funders for the present study & $\square 0$ & $\square 1$ \\
\hline
\end{tabular}

\section{Statistical analysis}

Meta-analysis was performed using the Review Manager version 5.0.25 (provided by the Cochrane Collaboration) and STATA package version 9.2 (Stata Corporation, College Station, TX, USA). The following contrasts for P53 Arg72Pro polymorphism were evaluated: the comparison of variant allele with ancestral allele (Pro allele $v s$ Arg allele); the comparison of each homozygote with the other combined with heterozygote (Pro/Pro vs Pro/Arg + Arg/ Arg; Arg/Arg vs Pro/Arg + Pro/Pro); the comparison of variant homozygote with ancestral 
homozygote and heterozygote (Pro/Pro vs Arg/Arg; Pro/Pro vs Pro/Arg). The strength of the associations between keloid risk and P53 Arg72Pro polymorphism was estimated by the odds ratio (OR) and 95\% confidence interval $(95 \% \mathrm{CI})$. Between-study heterogeneities were estimated using the Cochran Q test (Higgins and Thompson, 2002; Zintzaras and Ioannidis, 2005). We also quantified the effect of heterogeneity by using a recently developed measure, i.e., $I^{2}=100 \% \times(Q-$ d.f. $) / Q$. $I^{2}$ ranges between 0 and $100 \%$ and represents the proportion of inter-study variability that can be attributed to heterogeneity rather than chance. $\mathrm{I}^{2}$ values of 25,50 and $75 \%$ were defined as low, moderate and high estimates, respectively. When a significant $\mathrm{Q}$ test $(\mathrm{P}<0.10)$ or $\mathrm{I}^{2}>50 \%$ indicated heterogeneity across studies, the random effects model was used for meta-analysis, or else the fixed effects model was used. We tested whether genotype frequencies of controls were in HWE using the $\chi^{2}$ test. Subgroup analysis based on nationality was used to explore and to explain the diversity among the results of different studies. Publication bias was investigated by Begg's funnel plot, and funnel plot asymmetry was assessed by Egger's linear regression test (Peters et al., 2006); statistical significance was considered when the $\mathrm{P}$ value of the Egger test was $<0.05$. All the $\mathrm{P}$ values were two-sided. To ensure the reliability and accuracy of the results, two reviewers (Wu Y and Wang B) populated the data in the statistical software programs independently and got the same results.

\section{RESULTS}

\section{Studies included in the meta-analysis}

The search strategy retrieved 18 potentially relevant studies. According to the inclusion criteria, 6 studies with full-text were included in this meta-analysis (Jin et al., 2007; Yan et al., 2007; Liu, 2007, 2008; Zhuo et al., 2005, 2008) and 12 studies were excluded. A flow diagram illustrated the study selection procedure (Figure 1).

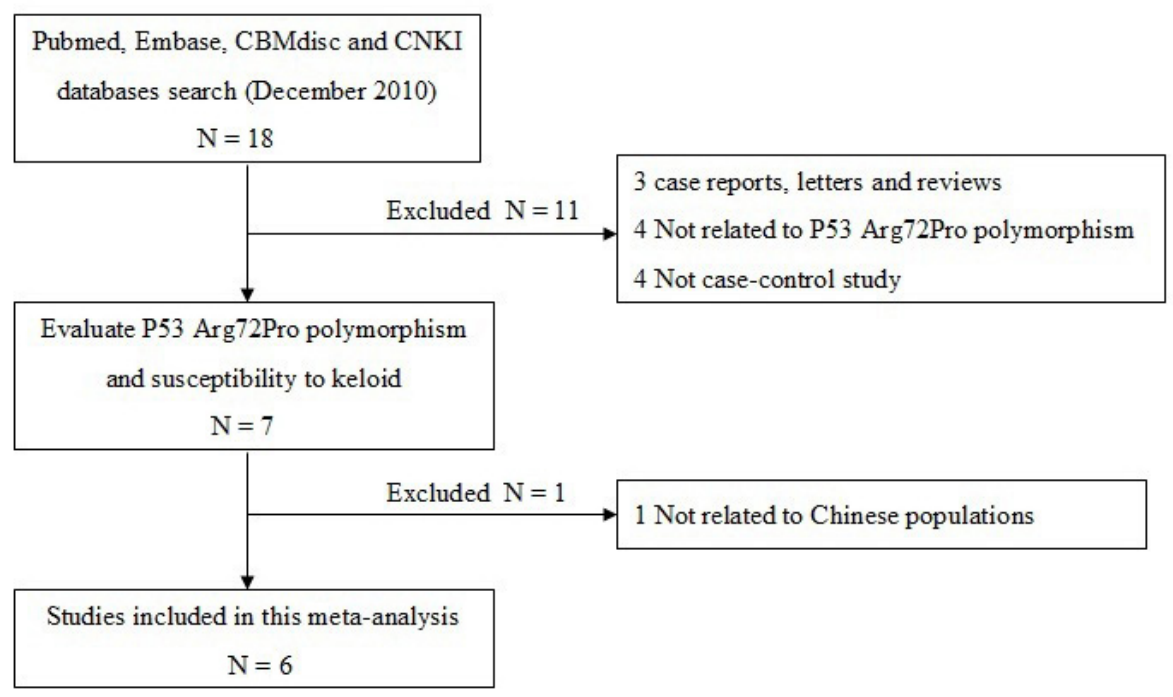

Figure 1. Flow chart showing study selection procedure. 
These 6 case-control studies selected included a total of 359 keloid cases and 493 healthy controls. All studies were case-control studies that evaluated the association of P53 Arg72Pro polymorphism and susceptibility to keloids. The publishing year of the included studies ranged from 2005 to 2008. All the articles were written in Chinese. HWE test was performed on genotype distribution of the controls in all studies included, and all of them were shown to be in HWE (P $>0.05$ ). The baseline characteristics and methodological quality of the selected studies are summarized in Table 2. The genotype distribution and risk allele frequency are summarized in Table 3.

\begin{tabular}{|c|c|c|c|c|c|c|}
\hline \multirow[t]{2}{*}{ First author (year) } & \multirow[t]{2}{*}{ Study design } & \multirow[t]{2}{*}{ Source of controls } & \multirow[t]{2}{*}{ Detection method } & \multicolumn{2}{|c|}{ Number of subjects } & \multirow[t]{2}{*}{ Quality score } \\
\hline & & & & Cases & Controls & \\
\hline Zhuo et al. (2005) & Case-control & Population-based & PCR-RDB & 45 & 60 & 23 \\
\hline Jin et al. (2007) & Case-control & Population-based & PCR-RDB & 52 & 52 & 15 \\
\hline Zhuo et al. (2008) & Case-control & Population-based & PCR-RDB & 75 & 75 & 21 \\
\hline Liu (2008) & Case-control & Population-based & PCR-RDB & 35 & 24 & 20 \\
\hline Yan et al. (2007) & Case-control & Population-based & PCR-RFLP & 60 & 102 & 24 \\
\hline Liu (2007) & Case-control & Population-based & PCR-RFLP & 92 & 180 & 22 \\
\hline
\end{tabular}

$\mathrm{PCR}=$ polymerase chain reaction; $\mathrm{RDB}=$ reverse dot blot; $\mathrm{RFLP}=$ restriction fragment length polymorphism.

Table 3. Genotype distribution and risk allele frequency of all studies included.

\begin{tabular}{|c|c|c|c|c|c|c|c|c|c|c|c|c|}
\hline \multirow[t]{2}{*}{ First author (year) } & \multicolumn{5}{|c|}{ Cases } & \multicolumn{5}{|c|}{ Controls } & \multicolumn{2}{|c|}{ HWE test } \\
\hline & No. & Arg/Arg & Arg/Pro & Pro/Pro & $\begin{array}{c}\text { Pro } \\
\text { (frequency) }\end{array}$ & No. & $\mathrm{Arg} / \mathrm{Arg}$ & Arg/Pro & Pro/Pro & $\begin{array}{c}\text { Pro } \\
\text { (frequency) }\end{array}$ & $\chi^{2}$ & $P$ value \\
\hline Zhuo et al. (2005) & 45 & 9 & 16 & 20 & 0.62 & 60 & 18 & 27 & 15 & 0.48 & 0.57 & 0.45 \\
\hline Jin et al. (2007) & 52 & 8 & 10 & 34 & 0.75 & 52 & 9 & 25 & 18 & 0.59 & 0.00 & 0.95 \\
\hline Zhuo et al. (2008) & 75 & 15 & 29 & 31 & 0.61 & 75 & 22 & 36 & 17 & 0.47 & 0.10 & 0.76 \\
\hline Liu (2008) & 35 & 7 & 21 & 7 & 0.50 & 24 & 18 & 6 & 0 & 0.13 & 0.49 & 0.48 \\
\hline Yan et al. (2007) & 60 & 19 & 33 & 8 & 0.41 & 102 & 28 & 49 & 25 & 0.49 & 0.15 & 0.70 \\
\hline Liu (2007) & 92 & 32 & 46 & 14 & 0.40 & 180 & 51 & 87 & 42 & 0.48 & 0.17 & 0.68 \\
\hline
\end{tabular}

HWE $=$ Hardy-Weinberg equilibrium.

\section{Main results and subgroup analysis}

Meta-analysis results identified no association between P53 Arg72Pro polymorphism and susceptibility to keloids in the comparisons: Pro allele $v$ s $\mathrm{Arg}$ allele $(\mathrm{OR}=1.57,95 \% \mathrm{CI}=0.92$ 2.69, $\mathrm{P}=0.10) ; \operatorname{Pro} / \operatorname{Pro} v s$ Pro/Arg $+\operatorname{Arg} / \operatorname{Arg}(\mathrm{OR}=1.60,95 \% \mathrm{CI}=0.73-3.53, \mathrm{P}=0.24) ; \mathrm{Arg} / \mathrm{Arg}$ vs Pro/Arg + Pro/Pro $(\mathrm{OR}=0.66,95 \% \mathrm{CI}=0.35-1.26, \mathrm{P}=0.21) ;$ Pro/Pro $v s \mathrm{Arg} / \mathrm{Arg}(\mathrm{OR}=1.58$, $95 \% \mathrm{CI}=0.636-3.75, \mathrm{P}=0.30)$, and Pro/Pro $v s \mathrm{Pro} / \mathrm{Arg}(\mathrm{OR}=1.56,95 \% \mathrm{CI}=0.71-3.42, \mathrm{P}=0.27)$.

In the subgroup analysis based on detection method, in which the studies respectively used polymerase chain reaction-reverse dot blot (PCR-RDB) and PCR-restriction fragment length polymorphism (PCR-RFLP), the results showed a significant association between P53 Arg72Pro polymorphism and susceptibility to keloids in the comparisons: Pro allele $v s$ Arg allele $(\mathrm{OR}=2.29,95 \% \mathrm{CI}=1.45-3.60, \mathrm{P}=0.0004 ; \mathrm{OR}=0.74,95 \% \mathrm{CI}=0.56-0.98, \mathrm{P}=0.04)$; Pro/Pro $v s$ Pro/Arg + Arg/Arg $(\mathrm{OR}=2.91,95 \% \mathrm{CI}=1.88-4.53, \mathrm{P}<0.0001 ; \mathrm{OR}=0.54,95 \% \mathrm{CI}$ $=0.32-0.92, \mathrm{P}=0.02) ;$ Pro/Pro $v$ s $\operatorname{Arg} / \operatorname{Arg}(\mathrm{OR}=2.79,95 \% \mathrm{CI}=1.54-5.06, \mathrm{P}=0.0007 ; \mathrm{OR}=$ $0.51,95 \% \mathrm{CI}=0.28-0.92, \mathrm{P}=0.03)$, and Pro/Pro $v s$ Pro/Arg $(\mathrm{OR}=2.85,95 \% \mathrm{CI}=1.75-4.63$, $\mathrm{P}<0.0001 ; \mathrm{OR}=0.57,95 \% \mathrm{CI}=0.32-0.99, \mathrm{P}=0.04)$. Nevertheless, no significant association was detected in comparisons of Arg/Arg vs Pro/Arg + Pro/Pro (Figures 2 and 3). 
$\mathbf{A}$

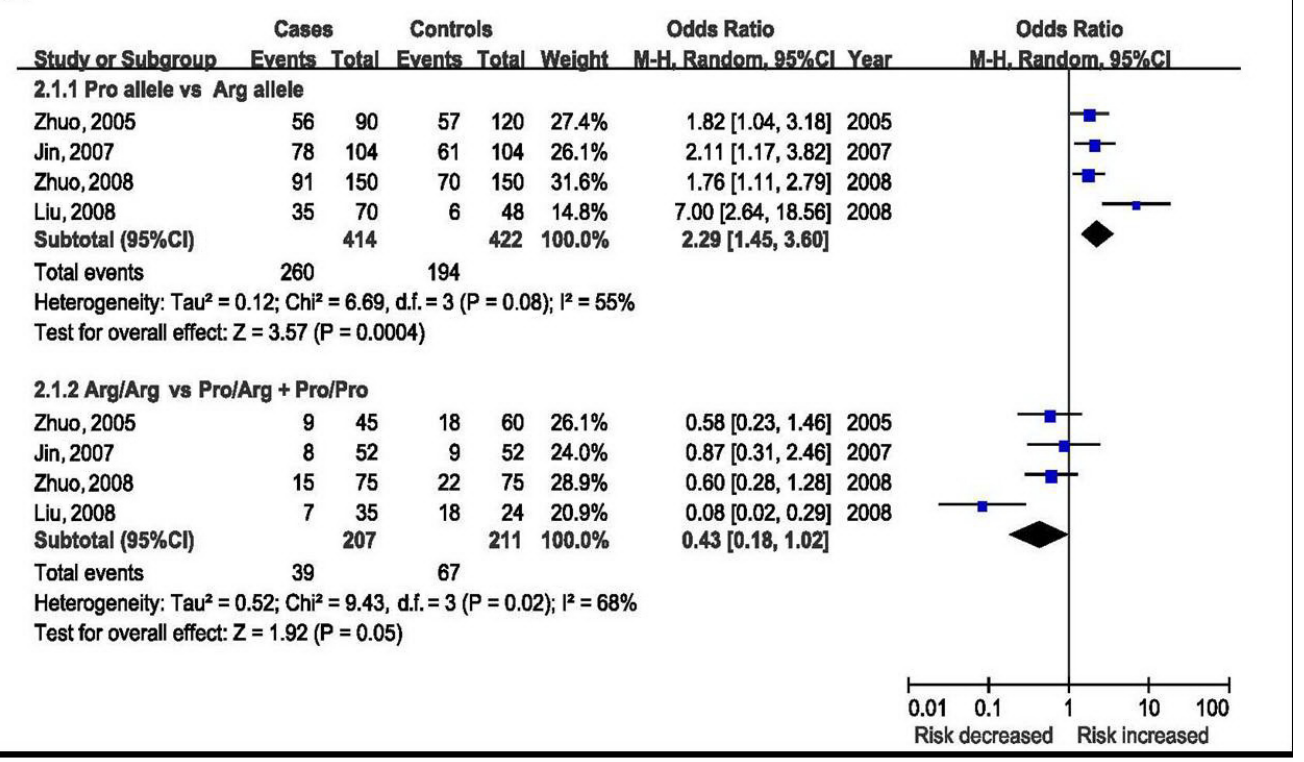

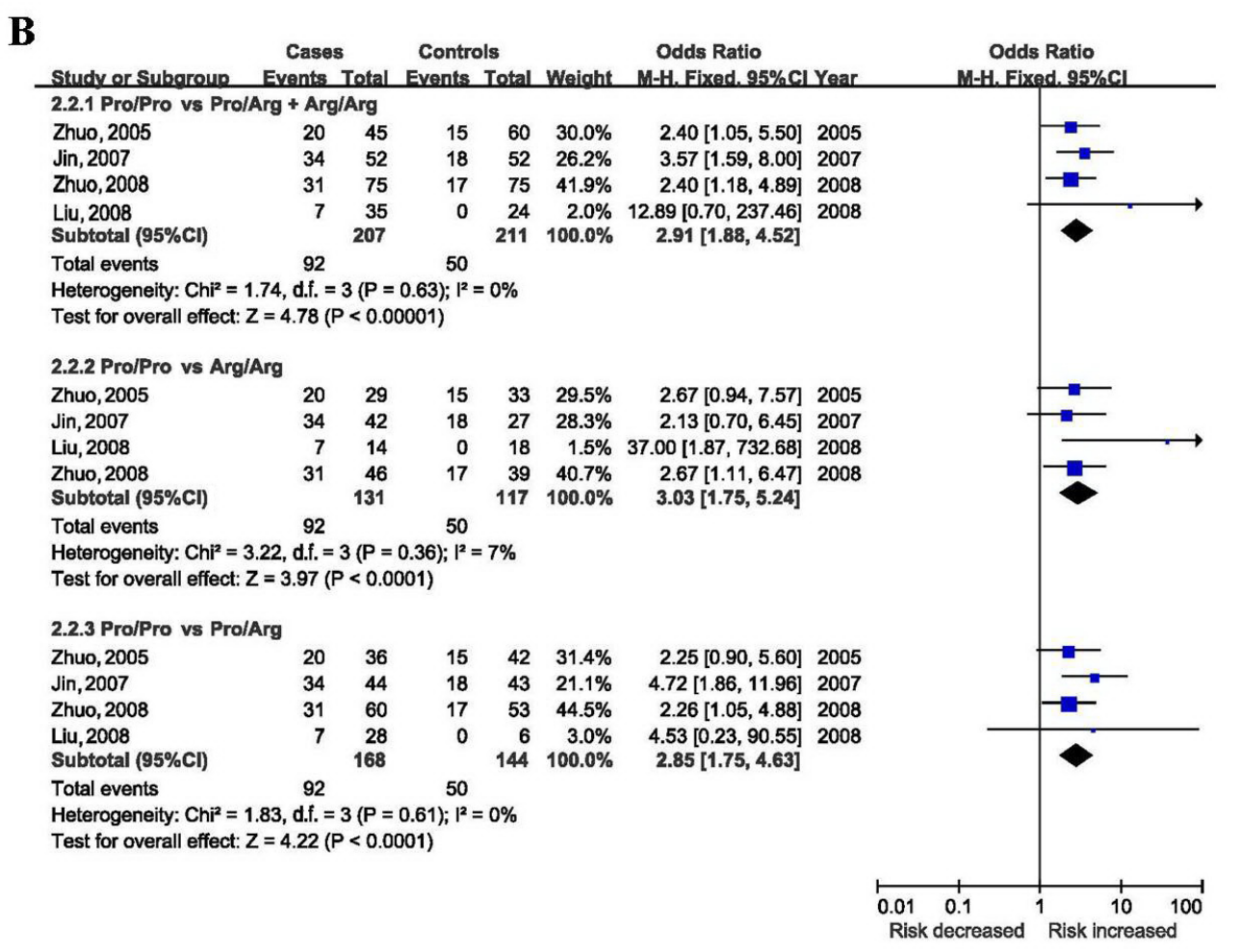

Figure 2. Subgroup analysis of studies using polymerase chain reaction-reverse dot blot detection method. A. Random model. B. Fixed model. 


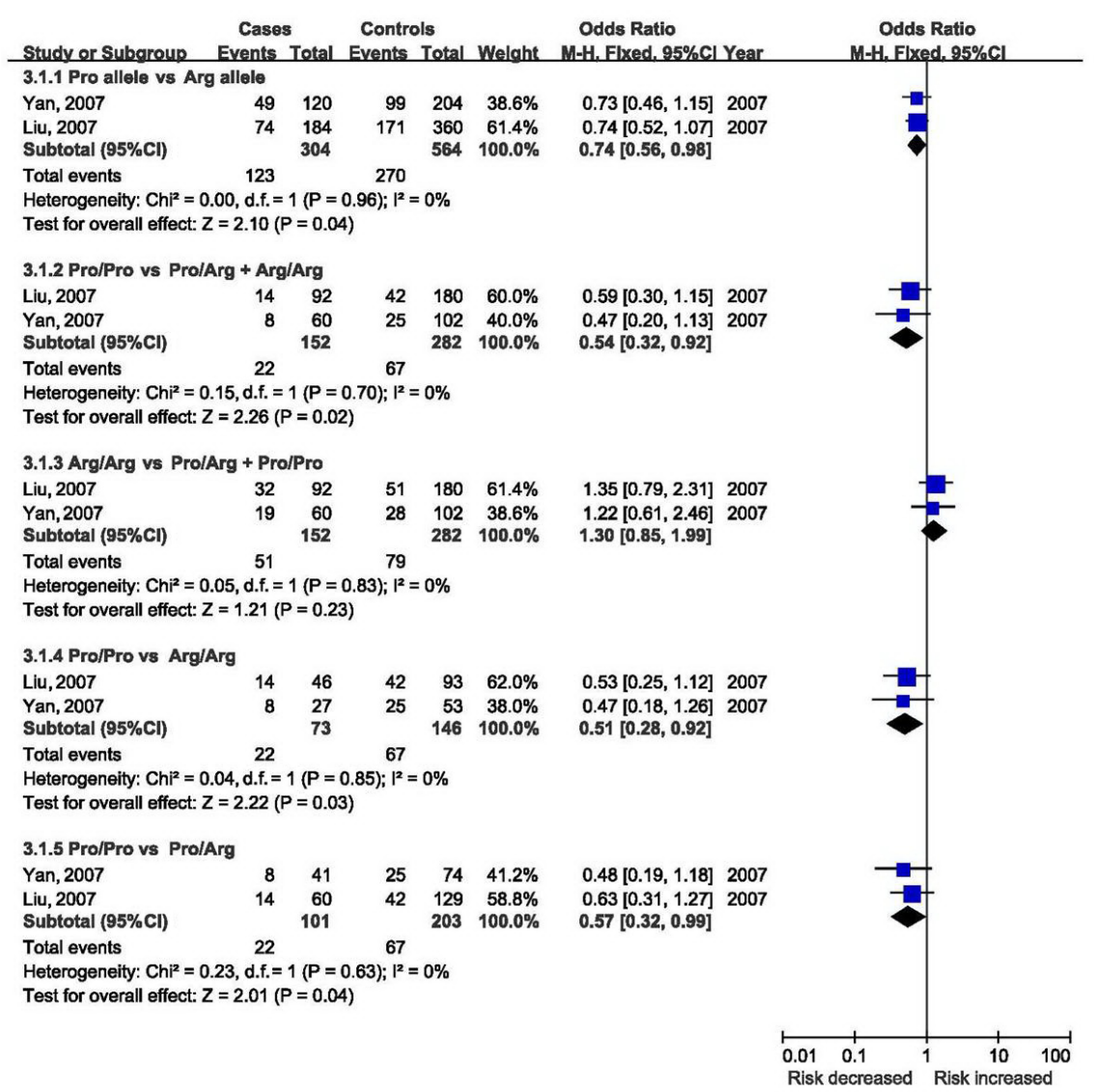

Figure 3. Subgroup analysis of studies using polymerase chain reaction-restriction fragment length polymorphism detection method.

\section{Publication bias}

Publication bias of the literature was accessed by Begg's funnel plot and the Egger test. The publication bias of the meta-analysis on the association between P53 Arg72Pro polymorphism and susceptibility to keloids was detected in all comparisons. Information on the Egger publication bias test is shown in Table 4.

Table 4. Egger publication bias test for P53 Arg72Pro polymorphism.

\begin{tabular}{|c|c|c|c|c|c|}
\hline Comparison & Coefficient & Standard error & $t$ & $P>|t|$ & $95 \% \mathrm{CI}$ \\
\hline Pro allele $v s$ Arg allele & 7.62 & 2.07 & 3.68 & 0.021 & $1.86 \sim 13.37$ \\
\hline Pro/Pro vs Pro/Arg + Arg/Arg & 2.17 & 2.97 & 0.73 & 0.506 & $-6.08 \sim 10.43$ \\
\hline Arg/Arg $v s$ Pro/Arg + Pro/Pro & -5.45 & 1.88 & -2.89 & 0.044 & $-10.67 \sim-0.22$ \\
\hline Pro/Pro $v s$ Arg/Arg & 3.69 & 2.20 & 1.68 & 0.168 & $-2.41 \sim 9.79$ \\
\hline Pro/Pro vs Pro/Arg & 1.75 & 2.80 & 0.62 & 0.566 & $-6.02 \sim 9.51$ \\
\hline
\end{tabular}




\section{DISCUSSION}

An Arg/Pro substitution at codon 72 in exon 4 is a common P53 gene polymorphism essential for P53-mediated apoptosis (Sakamuro et al., 1997). This polymorphism encodes the amino acids Pro and Arg, resulting in two structurally distinct forms of the protein (Matlashewski et al., 1987; Walker and Levine, 1996). Both forms are morphologically wild type and do not differ in their ability to bind to DNA in a sequence-specific manner (Thomas et al., 1999). However, the variants exhibit differences in their respective abilities to activate gene expression (Thomas et al., 1999).

Keloids represent a model of altered wound healing characterized by overproduction of extra-cellular matrix and dermal fibroblasts with high mitotic rate. Alteration of apoptosis and cell proliferation has been implicated in the etiology of keloids (Teofoli et al., 1999). Tanaka et al. (2004) demonstrated that the level of the P53 protein in keloid tissue was obviously high, accompanied by increased presence of fibroblasts, capillary vessels and infiltration of inflammatory cells. In 1998, Saed et al. identified P53 mutations in 7 keloid patients by PCR-SSCP analysis, subsequently confirmed by DNA sequencing. Other studies on Chinese populations also showed a hotspot mutation in the P53 gene exon 4 codon 72 of fibroblasts in keloids (Liu et al., 2003, 2004). A recent polymorphic study in Japanese populations indicated that the Arg/Arg genotype shows a risk for the piecing-induced ear-lobe keloid (Wang et al., 2005). Based on these findings, many Chinese studies have investigated the relationship between P53 Arg72Pro polymorphism and susceptibility to keloids.

In this meta-analysis, we quantitatively assessed the association between P53 Arg72Pro polymorphism and susceptibility to keloids. Finally, 6 case-control studies were included and comprised a total of 359 keloid cases and 493 healthy controls. The main meta-analysis results showed no significant association between P53 Arg72Pro polymorphism and susceptibility to keloids in the Chinese population. However, in the subgroup analysis, there was a significant association between P53 Arg72Pro polymorphism and susceptibility to keloids in the comparisons of Pro allele vs Arg allele, Pro/Pro vs Pro/Arg + Arg/Arg, Pro/Pro vs Arg/Arg, Pro/ Pro vs Pro/Arg in both the PCR-RDB subgroup and PCR-RFLP subgroup, indicating that the Pro allele and Pro/Pro homozygote of P53 Arg72Pro polymorphism may be a potential risk factor of keloids in the Chinese population. Different detection methods may be the source of heterogeneity.

There were some limitations in our meta-analysis. First, because of incomplete raw data or publication limitations, some relevant studies could not be included in our analysis. Second, we were not able to address the sources of heterogeneity existing among studies for each polymorphism. Third, we could not perform further subgroup stratifications analysis because of the limited number of published studies. In addition, the small sample size available was not ideal for detecting small genetic effects. Finally, our systematic review was based on unadjusted data, as the genotype information stratified for the main confounding variables was not available in the original papers, and also, the confounding factors addressed across the different studies were variable.

In conclusion, our meta-analysis of all 6 case-control studies demonstrated that the Pro allele and Pro/Pro homozygote of P53 Arg72Pro polymorphism could be a potential risk factor of keloids in the Chinese population. As some limitations may undoubtedly affect our final conclusions, larger and confirmatory studies are needed to clarify the role of constitutional polymorphisms in the $P 53$ gene and keloid risk. 


\section{ACKNOWLEDGMENTS}

Research supported by the Fund for Ministry of Education in Colleges and Universities (code \#20102104120007).

\section{REFERENCES}

Al-Attar A, Mess S, Thomassen JM, Kauffman CL, et al. (2006). Keloid pathogenesis and treatment. Plast. Reconstr. Surg. 117: 286-300.

Atiyeh BS, Costagliola M and Hayek SN (2005). Keloid or hypertrophic scar: the controversy: review of the literature. Ann. Plast. Surg. 54: 676-680.

Bayat A, McGrouther DA and Ferguson MW (2003). Skin scarring. BMJ 326: 88-92.

Butler PD, Longaker MT and Yang GP (2008). Current progress in keloid research and treatment. J. Am. Coll. Surg. 206: 731-741.

De Felice B, Ciarmiello LF, Mondola P, Damiano S, et al. (2007). Differential p63 and p53 expression in human keloid fibroblasts and hypertrophic scar fibroblasts. DNA Cell Biol. 26: 541-547.

Higgins JP and Thompson SG (2002). Quantifying heterogeneity in a meta-analysis. Stat. Med. 21: 1539-1558.

Jin J, Gao JH and Lu F (2007). Clinical experiment of susceptible people to keloid. Zhongguo Lin Chuang Jie Pao Xue Za Zhi 25: 320-322.

Ladin DA, Hou Z, Patel D, McPhail M, et al. (1998). p53 and apoptosis alterations in keloids and keloid fibroblasts. Wound Repair Regen. 6: 28-37.

Liu Y (2007). Preliminary Linkage Analysis of Keloid Susceptibility Loci and Polymorphisms of Correlation Genes in Chinese Han Population. Master's thesis, China Medical University, Shenyang.

Liu YB (2008). The Study of Impaired Apoptosis Function of Fas and P53 Protein in the Fibroblasts Derived from Keloid. $\mathrm{PhD}$ thesis, Southern Medical University, Guangzhou.

Liu YB, Gao JH, Duan HJ and Liu XJ (2003). Investigation of p53 gene mutations in keloids using PCR-SSCP. Zhonghua Zheng Xing Wai Ke Za Zhi 19: 258-260.

Liu W, Jiang YH, Li YL, Lin ZH, et al. (2004). Experimental study on p53 gene mutation in keloid fibroblasts. Zhonghua Shao Shang Za Zhi 20: 85-87.

Marneros AG and Krieg T (2004). Keloids-clinical diagnosis, pathogenesis, and treatment options. J. Dtsch. Dermatol. Ges. 2: 905-913.

Matlashewski GJ, Tuck S, Pim D, Lamb P, et al. (1987). Primary structure polymorphism at amino acid residue 72 of human p53. Mol. Cell Biol. 7: 961-963.

McGregor JM, Harwood CA, Brooks L, Fisher SA, et al. (2002). Relationship between p53 codon 72 polymorphism and susceptibility to sunburn and skin cancer. J. Invest. Dermatol. 119: 84-90.

Menezes HL, Juca MJ, Gomes EG, Nunes BL, et al. (2010). Analysis of the immunohistochemical expressions of p53, bcl-2 and Ki-67 in colorectal adenocarcinoma and their correlations with the prognostic factors. Arq. Gastroenterol. 47: 141-147.

Peters JL, Sutton AJ, Jones DR, Abrams KR, et al. (2006). Comparison of two methods to detect publication bias in metaanalysis. JAMA 295: 676-680.

Pezeshki A, Sari-Aslani F, Ghaderi A and Doroudchi M (2006). p53 codon 72 polymorphism in basal cell carcinoma of the skin. Pathol. Oncol. Res. 12: 29-33.

Saed GM, Ladin D, Olson J, Han X, et al. (1998). Analysis of p53 gene mutations in keloids using polymerase chain reaction-based single-strand conformational polymorphism and DNA sequencing. Arch. Dermatol. 134: 963-967.

Sakamuro D, Sabbatini P, White E and Prendergast GC (1997). The polyproline region of p53 is required to activate apoptosis but not growth arrest. Oncogene 15: 887-898.

Sayah DN, Soo C, Shaw WW, Watson J, et al. (1999). Downregulation of apoptosis-related genes in keloid tissues. $J$. Surg. Res. 87: 209-216.

Sjalander A, Birgander R, Kivela A and Beckman G (1995). p53 polymorphisms and haplotypes in different ethnic groups. Hum. Hered. 45: 144-149.

Tanaka A, Hatoko M, Tada H, Iioka H, et al. (2004). Expression of p53 family in scars. J. Dermatol. Sci. 34: 17-24.

Teofoli P, Barduagni S, Ribuffo M, Campanella A, et al. (1999). Expression of Bcl-2, p53, c-jun and c-fos protooncogenes in keloids and hypertrophic scars. J. Dermatol. Sci. 22: 31-37.

Thomas M, Kalita A, Labrecque S, Pim D, et al. (1999). Two polymorphic variants of wild-type p53 differ biochemically 
and biologically. Mol. Cell Biol. 19: 1092-1100.

Vandenbroucke JP, von Elm E, Altman DG, Gotzsche PC, et al. (2007). Strengthening the Reporting of Observational Studies in Epidemiology (STROBE): explanation and elaboration. Epidemiology 18: 805-835.

Walker KK and Levine AJ (1996). Identification of a novel p53 functional domain that is necessary for efficient growth suppression. Proc. Natl. Acad. Sci. U. S. A. 93: 15335-15340.

Wang CM, Hiko H and Nakazawa N (2005). Investigation of p53 polymorphism for genetic predisposition of keloid and hypertrophic scar. Zhonghua Zheng Xing Wai Ke Za Zhi 21: 32-35.

Yan L, Lu XY, Wang CM, Cao R, et al. (2007). Association between p53 gene codon 72 polymorphism and keloid in Chinese population. Zhonghua Zheng Xing Wai Ke Za Zhi 23: 428-430.

Zhuo Y, Gao JH, Luo SQ, Zeng WS, et al. (2005). p53 gene codon 72 polymorphism and susceptibility to keloid. Zhonghua Zheng Xing Wai Ke Za Zhi 21: 201-203.

Zhuo Y, Gao JH and Zeng XY (2008). The application of P53 gene detection kit for susceptibility of keloid. Zhongguo Mei Rong Yi Xue 5: 694-696.

Zintzaras E and Ioannidis JP (2005). Heterogeneity testing in meta-analysis of genome searches. Genet. Epidemiol. 28: 123-137. 